\title{
All Hands on Deck: The Sea as an Object to Rethink Migrations. An Introduction
}

Marta Silva and Yvette Santos

\section{OpenEdition}

\section{Journals}

Electronic version

URL: https://journals.openedition.org/rccs/12118

DOI: $10.4000 /$ rccs. 12118

ISSN: 2182-7435

Publisher

Centro de Estudos Sociais da Universidade de Coimbra

\section{Printed version}

Date of publication: 1 September 2021

Number of pages: 101-106

ISSN: 0254-1106

\section{Electronic reference}

Marta Silva and Yvette Santos, "All Hands on Deck: The Sea as an Object to Rethink Migrations. An Introduction", Revista Crítica de Ciências Sociais [Online], 125 | 2021, Online since 30 September 2021, connection on 03 October 2021. URL: http://journals.openedition.org/rccs/12118 ; DOI: https:// doi.org/10.4000/rccs. 12118 


\section{All Hands on Deck: The Sea as an Object to Rethink Migrations. An Introduction*}

The thematic dossier "All Hands on Deck: The Sea as an Object to Rethink Migrations" proposes an approach to different ways of understanding migratory movements through their presence at sea. This dossier is part of the oceanic turn, its focus being the sea and its methodology removing the exclusivity of land marked by a visible border. Thinking about the complexity that the sea represents in the past and in the present, it allows a polychromatic reading of the Human/Territory relationship as well as providing a reading of space and time. It is a unique space, of connections and interconnections, of obstacles, but, above all, of ambiguities, promoted by the action of those who cross it, those who want to control it or those who appropriate it only from the viewpoint of a dream, or else symbolically.

Population movements, regardless of their nature or motivation, lead individuals, States or future nations to (re)interpret and (re)organise the spaces in which they interact, symbolically or materially. In this involvement of different geopolitical and ideological players and stakes, etched in long and suspended times and at multiple distances, it is necessary to question how and for what purposes the sea is appropriated, (re)defined or (re)constructed by the various historical subjects.

We start from the idea that the sea is, simultaneously, a unique element and a creator of specificities, and that, as such, it is used by migratory movements as a means of fulfilling a trajectory, transmitting messages or signalling intentions, as we can see in the processes of construction of national identities. Now, the idiosyncrasies of the sea justify, from the outset, that we challenge the definition of the maritime border itself, since we are facing chronologies where the original principle of freedom of the seas is already obsolete. As such, addressing the concept of a maritime border

* This text and the edition of the thematic dossier are associated with the project UID/ /HIS/04209/2013, funded by the Portuguese Foundation for Science and Technology. 
implies accepting the flexibility to which it is subjected according to its (un)desirable permeability and according to its importance in the affirmation, reinforcement or reformulation of identities. Likewise, it is important to face the identities and cultures constructed from the sea, as well as the migratory movements that use it, as transnational and connected objects of study, thus surpassing the borders of the nation-state.

The approaches followed in this thematic dossier are, above all, transnational. However, an overall reading of the articles reveals the shared modes of action of the dominant social forces, the standardisation of behaviours, discourses and representations within nationalistic and discriminatory cultures in relation to subordinated groups or territories; that is, first of all, the interconnections and reproductions of the processes of appropriation of the sea are the starting point for an approach that is also global.

The best way to navigate these waters is also to free them from disciplinary boundaries. Therefore, this dossier intends to underline the importance of creating and following alternative perspectives for the understanding of migratory phenomena and the sea and, specifically, these phenomena in the sea. We sought, therefore, for politics, ethics and aesthetics to converse and occupy a central position in the reflection resulting from the reading of the texts.

The dialogue between the different disciplines is enriched by the uniqueness of the required methodologies. Historical sources not only show the role and position of the dominant social forces - their thoughts and their strategies for action - but also give voice to the most fragile and subordinate subjects who take to the sea, and paradoxically, provide a possibility of survival in the midst of the danger they face. Film production is also presented as an indispensable source, in this case for understanding the current migratory crisis. The films, in addition to their solid content about migratory phenomena, at the same time fulfil the role of a mobilising art, a critic and a producer of contents which generate a myriad of possible interpretations about emotions aimed at humanising migrations. This triggering of emotions is also a valid means of provoking and awakening ethical imperatives and the mechanisms of inclusion/exclusion in a space - the sea - which confronts subjects with subjective perceptions and legitimacy.

With this set of texts, we would like, therefore, to open clues to new paths of reflection, to new ways of perceiving these phenomena and, simultaneously, making available, not only for the academics, but also for individuals and state/institutional entities, tools for an awareness of human enjeux and, particularly, the humanisation of migratory movements. The barriers that we intend to break down here are, therefore, part of the current challenges 
raised by international human mobilities and which have been promoting a multi-scale and multidisciplinary scientific reflection, which is supposed to be separated from political, mediatic or even from some academic discourses. Thus, knowledge of the sea has been reduced to a border or an environment conducive to the practice of criminal activities related, especially, with regard to migrations. These readings are actually converging towards the (re)birth or perpetuation of nationalisms and the increase of racism, xenophobia and discrimination.

Launching a dialogue between works from disciplines arising from the area of social and human sciences is, therefore, also a way to demonstrate the blurring of major ideological or conceptual ruptures between past and present, and to show patterns or lines of continuity in the processes of (de) construction of the identity of the "nation". Furthermore, this set of articles also raises the question of the legitimacy of this construction, taking into account the globality of migratory movements and their motivations. Of course, and according to the historians Donna R. Gabaccia and Dirk Hoerder (2011), the intention is not to annihilate the role of nation-states in international and maritime mobilities; on the contrary, it is intended to highlight their paradigms and their dialogue with other players and stakeholders, with their own modes of intervention and actions.

The format that translates the aims mentioned so far is composed of four articles. Each of them adopts different analytical perspectives on migrations by sea, shaped by the areas of expertise but without being closed to others. From history, passing through philosophy and art, to linguistics, a set of works were gathered that reflect on migrations, the sea and on the political-ideological and artistic "uses" in contexts that reveal significant factors in its appropriation/occupation processes: in national and international frameworks of tension and conflict in a globalised world, and in periods of tightening of border control.

The Mediterranean area was given pride of place by the authors of this dossier, which, in recent years and as a result of recent migratory crises, has stimulated a growing scientific interest. Its weight also arises from the original context of this work. This proposal has been matured during the course of the project "The Social and Economic Integration of Refugees in Portugal: A Normative Assessment of Moral Duties, Public Policies, and Social Values" and the International Conference "The Sea in the $20^{\text {th }}-21^{\text {st }}$ Centuries and the 'Forbidden Migrations"', which took place in November 2019.

\footnotetext{
1 This project was funded by the Portuguese Foundation for Science and Technology under grant PTDC/FER-ETC/30378/2017 and coordinated by Gabriele De Angelis.
} 
In both of them the sea was the central issue in all questions about migrations and political discourse, practices of securitisation of borders, personal narratives, life stories, individual and collective traumas, and practices of facilitation and intermediation of illegal migrations and identity construction. The Mediterranean space was one of the most analysed, followed by migrations across the Atlantic.

However, that sea serves as a mirror to what is observed in other maritime spaces and historical migratory movements, such as the European transatlantic migrations of the $19^{\text {th }}$ and $20^{\text {th }}$ centuries. What is intended here is rather to highlight the singularities and similarities in the different processes of appropriation of the sea, contemplating a closed maritime space (the Mediterranean) and an open maritime space (the Atlantic). Such a crossover also provides a privileged understanding of the relations between centre-periphery and between North-South. This option, even if it has the Eurasian continent in common, presents it as both a point of arrival and a point of departure, where stands out, after all, a great South, of which its populations are in search of opportunities and alternatives throughout history. Indeed, the analysis of the "maritime space", crossed with the studies of migrations, alerts us, once again, to the existence of a South which continues to be subjected to mechanisms that weaken its populations (Santos, 2013: 240-276).

This thematic dossier follows three axes. The first presents the sea as a guarantor of cohesion and affirmation of national sovereignty and as a privileged instrument for re-establishing the balance of powers, at a national and international level. In this axis, we analyse how the sea is used as a means to ensure the survival and rejuvenation of identity or the construction of a nation, bearing in mind that migrations which take place by sea sometimes reinforce and sometimes weaken national borders and ensure the physical and ideological appropriation of territories - a legacy of the thought and practice of colonial domination in the construction of nation-states. A second axis aims to encourage a critical reflection on the role of the arts as a form of expression and representation of migrants in maritime spaces - spaces that belong to humankind and, therefore, need to be seen within and beyond migratory crises. Finally, in the third axis, we intend to look at the different strategies developed to overcome the obstacles described before, in order to understand to what extent the sea is at the centre of reviving the relationship between the diaspora and the State of origin, provided by the degradation of the condition of being subordinated, and the precariousness of migrants in a context of instability or political and economic crisis in the country of destination.

These three axes are followed up by the four authors, who demonstrate and dismantle the panoply of discourses and representations about 
(un)desired migratory movements and propose new ways of reading migrations based on the analysis of different languages. Alicia Gil Lázaro proposes an analysis of migrations based on the perceptions which the Spanish migrants settled in Mexico City have about their goals and life projects, mediated by the distances imposed by inland territories and the Atlantic Ocean. The author crosses classic archival sources - which show the political-economist language of the Spanish State and of businesses related to the transport of migrants - with the voices of those migrants contained in letters addressed to the consular authorities. These documents highlight the clues that provide access to the place that the sea occupied in the migrants' imagination and in their relationship with the State of origin.

While in Gil Lázaro the Spanish migrants are the protagonists of history, Björn Siegel focuses on the ideological conflicts within the Zionist movement and on the existing differences between the narrative of Jewish state-building through immigration and the British perspective on migratory movements for that region. Siegel's work on the geostrategic and Zionist narrative in relation to the sea at the dawn of the creation of the Jewish nation in Israel highlights, precisely, the thought and discourse of the political-intellectual elite on the importance of maritime control of the Mediterranean, and the management of movements that cross it.

Precisely with the aim of enriching or bringing a new perspective to political discourses and practices, and cultural perceptions, Emma De Angelis and Gabriele De Angelis, about the recent migratory movements that enter Europe, opt for a logic of deconstruction of national-European territories. Based on the analysis of cinematographic languages, the authors analyse and attest the importance of artistic creation and aesthetic production as vehicles for transmitting and exposing ethical concerns and political messages that help to rethink the axes that move the political framework made on the migratory movements which are perceived as unwanted.

And it is with a proposal for a denser and more critical reading, confronting contemporaneity and historical belonging, on the same public perceptions and migration policies applied to immigration candidates trying to enter Europe through the Mediterranean that we close the dossier. Graziele Frederico "took out" from the Abbecedario delle migrazioni (2018), edited by Luca Barbari and Francesco De Vanna, some entries to demonstrate the violations that have taken place in the Mediterranean. According to an analysis of these entries, the author proposes a practical lexicon that reinforces the idea of a shared and open sea. Based on content that, according to its editors, can be gleaned from a technical-juridical reading in which concepts are understood from their political-legal sense or from 
an understanding of human existence itself as a journey (Pattin, 2020:354), and having as a reference the idea of a historical collective belonging of the sea proposed by Fernand Braudel, Frederico ends up exploring the concept of mare nostrum through its migratory movements. The historical journey through the language associated with the Mediterranean has once again highlighted the ethical and legal violations to which migrants who navigate this sea are subjected.

Edited by Timothy Hinchey

\title{
References
}

Gabaccia, Donna R.; Hoerder, Dirk (eds.) (2011), Connecting Seas and Connected Ocean Rims. Indian, Atlantic, and Pacific Oceans and China Seas Migrations from the 1830s to the 1930s. Leiden/Boston: Brill.

Pattin, Sebastián (2020), "Recensiones - Luca Barbari, Francesco De Vanna (eds.), "Il 'diritto al viaggio'. Abbecedario delle migrazioni, Colección 'Diritto e Vulnerabilità Studi e ricerche del CRID' Giappichelli, Turin, 2018, pp. 347”, Derechos y Libertades, 43(II), 353-357.

Santos, Boaventura de Sousa (2013), Pela mão de Alice. O social e o político na pós-modernidade. Coimbra: Edições Almedina.

\author{
Marta Silva \\ Instituto de História Contemporânea, Faculdade de Ciências Sociais e Humanas, \\ Universidade NOVA de Lisboa \\ Avenida de Berna, 26-C, 1069-061 Lisboa, Portugal \\ Contact: silvamartanunes@gmail.com \\ ORCID: https://orcid.org/0000-0001-5133-3284
}

\section{Yvette Santos}

Instituto de História Contemporânea, Faculdade de Ciências Sociais e Humanas, Universidade NOVA de Lisboa Avenida de Berna, 26-C, 1069-061 Lisboa, Portugal

Contact: yvettedossantos@gmail.com

ORCID: https://orcid.org/0000-0003-4264-8182

https://doi.org/10.4000/rccs. 12118

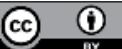

